Annals of International Medical and Dental Research

E-ISSN: 2395-2822 | P-ISSN: 2395-2814

Vol-8, Issue-2 | March-April 2022

DOI: 10.53339/aimdr.2022.8.2.23

Page no- 174-179 | Section- Research Article (Otolaryngology)

\title{
Adenotonsillectomy Operation in Children is Effective to Improve Otitis Media with Effusion
}

\author{
Md. Mostafa Kamal Hossain Bhuiyan ${ }^{1 *}$, Salma Hossain², Mohammad Amzad Hossain ${ }^{3}$, \\ Mohammad Anamul Haque ${ }^{4}$
}

\begin{abstract}
${ }^{1}$ Assistant Professor, Department of Otolaryngology, Shaheed Tajuddin Ahmed Medical College, Gazipur, Bangladesh.

Email: ahnaf09september2008@gmail.com

Orcid ID: 0000-0003-4354-7447

${ }^{2}$ Assistant Professor, Department of Pediatrics \& Neonatology, Ashiyan Medical College Hospital, Dhaka, Bangladesh.

Email: dr.salmahossain@gmail.com

Orcid ID: 0000-0002-8050-5863

${ }^{3}$ Associate professor, Department of Otolaryngology, Shaheed Tajuddin Ahmed Medical College Gazipur, Bangladesh.

Email: dramzadent71@gmail.com

Orcid ID: 0000-0002-7011-5204

${ }^{4}$ Assistant Professor, Department of ENT \& Head Neck surgery, Shaheed Tajuddin Ahmad Medical College, Gazipur, Bangladesh.

Email: dranament@gmail.com

Orcid ID: 0000-0002-5221-126X

*Corresponding author

Received: 26 November 2021

Revised: 22 January 2022

Abstract

Background: OME usually present because of the associated hearing impairment, defective speech and sometimes with a preceding history of fever and otalgia consequent on an episode of acute otitis media. Objective: The aim of the study was to evaluate adenotonsillectomy operation in children is effective to improve otitis media with effusion. Material \& Methods: This was a clinical study done in the otolaryngology department of medical college for women and hospital, Uttara, Dhaka from January 2003 to December 2005 for three years. Children with 4 to 15 years of age admitted with chronic tonsillitis and enlarged adenoid having otitis media with effusion were included in the study. Statistical analysis of the results was obtained by using window-based computer software devised with Statistical Packages for Social Sciences (SPSS-22). Results: All of these patients underwent adenotonsillectomy operation and were followed up for up to six months. The overall success rate of resolution of middle ear effusion was $81 \%$ at six months post operatively. Conclusions: Our findings demonstrated that adenotonsillectomy operation is effective for the treatment of persistent otitis media with effusion due to chronic tonsillitis with enlarged adenoid.
\end{abstract}

Accepted: 02 February 2022

Published: 18 February 2022

Keywords:- Adenoids; adenoidectomy; tonsillectomy, otitis media with effusion.

\section{INTRODUCTION}

The prevalence of recurrent tonsillitis with enlarged adenoids, which causes otitis media with effusion (OME) peaks between the ages of 4 to 10 years. Enlarged adenoids in children cause otitis media with effusion. Half of all children with enlarged adenoid aged 3 to 5 years have at least one effusion per year, and between 28 and $38 \%$ of preschool children experience a recurrence of OME.[1,2,3] Approximately $50 \%$ of effusions resolve spontaneously within 2 months, but $5 \%$ result in a bilateral conductive hearing loss that persists for at least 1 year, and that can cause subsequent language impairments and learning difficulties. $[4,5,6,7]$ Others have reported spontaneous resolution at 2 to 3 years in $31 \%$ of patients with untreated OME. $[2,8]$ Among the factors that can hinder the resolution of OME 
Annals of International Medical and Dental Research

E-ISSN: 2395-2822 | P-ISSN: 2395-2814

Vol-8, Issue-2 | March-April 2022

DOI: 10.53339/aimdr.2022.8.2.23

Page no- 174-179 | Section- Research Article (Otolaryngology)

are recurrent acute infection, atopic disease .and enlarged adenoids. $[1,6,9]$ Persistent OME (glue ear) is a common cause of hearing loss in children.[10] In the United Kingdom, five of every 1,000 children require surgery for this condition at an annual cost of 30 million pounds sterling. [11] In the United States the cost of such surgery reaches 2 billion US dollar per year.[11] Children with persistent bilateral OME are more likely to experience language impairments, which can lead to learning and behavioral problems. These problems can continue to affect the academic performance and development of these children well into the future.[12] There is controversy regarding the treatment of OME. Treatment options range from medical therapies to different types of surgical procedures. Although combination of antibiotics, decongestants and corticosteroids clear effusions, the recurrence rate is high once treatment in discontinued. Several surgical procedures reduce OME induced hearing loss but they do not always cure persistent bilateral effusion.[13]

In our study, we attempted to determine the effectiveness of adenotonsillectomy operation in a group of children with persistent otitis media with effusion who had failed medical treatment and who had no history of ear surgery.

\section{MATERIAL AND METHODS}

This was a clinical study done in the otolaryngology department of medical college for women and hospital, Uttara, Dhaka from January 2003 to December 2005 for three years. Children with 4 to 15 years of age admitted with chronic tonsillitis and enlarged adenoid having otitis media with effusion were included in the study. Cases with OME improved with medical treatment and patients had history of ear surgery were excluded from the study. Audiological tests were performed in all the cases. Diagnosis was confirmed from history, clinical examination and investigations. All the patients underwent adenotonsillectomy operations and were followed up for six months. The effect of adenotonsillectomy operations for the treatment of OME were observed and discussed in this study. Statistical analysis of the results was obtained by using windowbased computer software devised with Statistical Packages for Social Sciences (SPSS22).

\section{RESULTS}

We studied 100 children aged 4 to 15 years, who had recurrent tonsillitis, enlarged adenoids, persistent bilateral middle ear effusion and bilateral conductive hearing loss of 2 to 12 months duration and a history of snoring at night.

Patients were diagnosed and selected for surgery on the basis of their history, otoscopic examination, audiometry and tympanometry results, x-ray nasopharynx lateral view and their failure to respond to at least three months of medical treatment. Otoscopically the tympanic membrane was dull and immobile in all patients but four patient \& in two of these patients, the tympanic membranes were difficult to see, and in the other two, the membranes were retracted, x-ray nasopharynx lateral view revealed that all patients had a narrowing of the nasopharyngeal airway as a result of an enlargement of the adenoids. Audiograms showed that there was significant 
Annals of International Medical and Dental Research E-ISSN: 2395-2822 | P-ISSN: 2395-2814

Vol-8, Issue-2 | March-April 2022

DOI: 10.53339/aimdr.2022.8.2.23

Page no- 174-179 | Section- Research Article (Otolaryngology)

air-bone gap that are conductive hearing loss in all patients. Tympanograms were fiat type B in all patients [Figure 1].

All the patients underwent adenotonsillectomy under general anesthesia. Postoperative follow up were performed for up to six months postoperatively. Criteria for success included a subjective improvement in hearing; findings on otoscopic examination, and closure of the air- bone gap within three months of surgery [Figure 2].

It was observed that 81 children out of 100 cases had improvement in their middle ear effusion \& hearing loss. The rest 19 cases, 5 patients were lost from follow up and 12 cases were not improved and needed myringotomy operation.

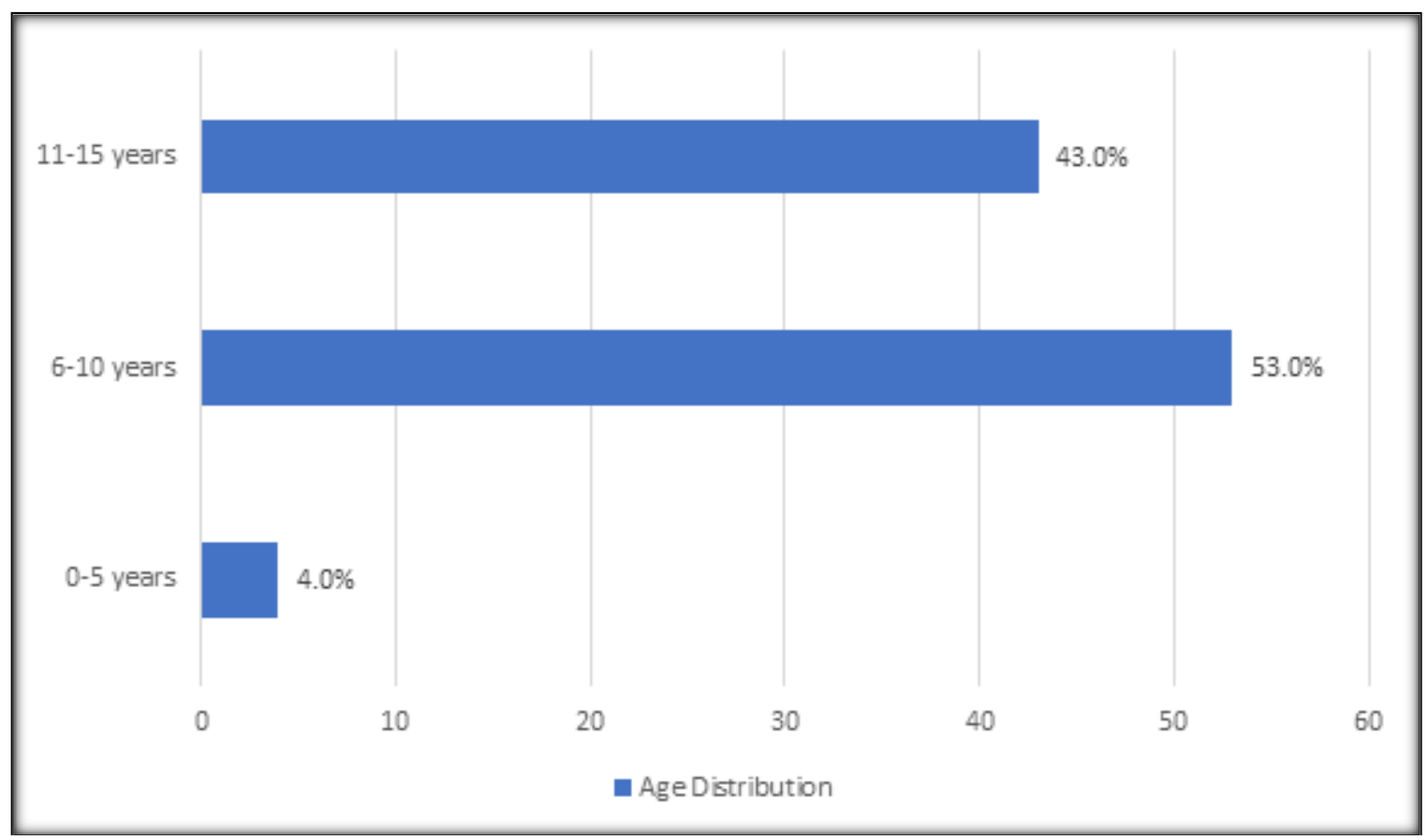

Figure 1: Demonstrate and distribution of the study according to age.

Table 1: Distribution of clinical features of the study

\begin{tabular}{|l|l|l|}
\hline Clinical Features & $\mathbf{n = 1 0 0}$ & $\mathbf{\%}$ \\
\hline 1. Recurrent tonsillitis with adenoid & 100 & 100.0 \\
\hline 2. Bilateral Middle Ear Effusion & 100 & 100.0 \\
\hline 3. Bilateral Conductive hearing loss & 100 & 100.0 \\
\hline 4. Snoring at Night & 70 & 70.0 \\
\hline
\end{tabular}


Annals of International Medical and Dental Research E-ISSN: 2395-2822 | P-ISSN: 2395-2814

Vol-8, Issue-2 | March-April 2022

DOI: 10.53339/aimdr.2022.8.2.23

Page no- 174-179 | Section- Research Article (Otolaryngology)

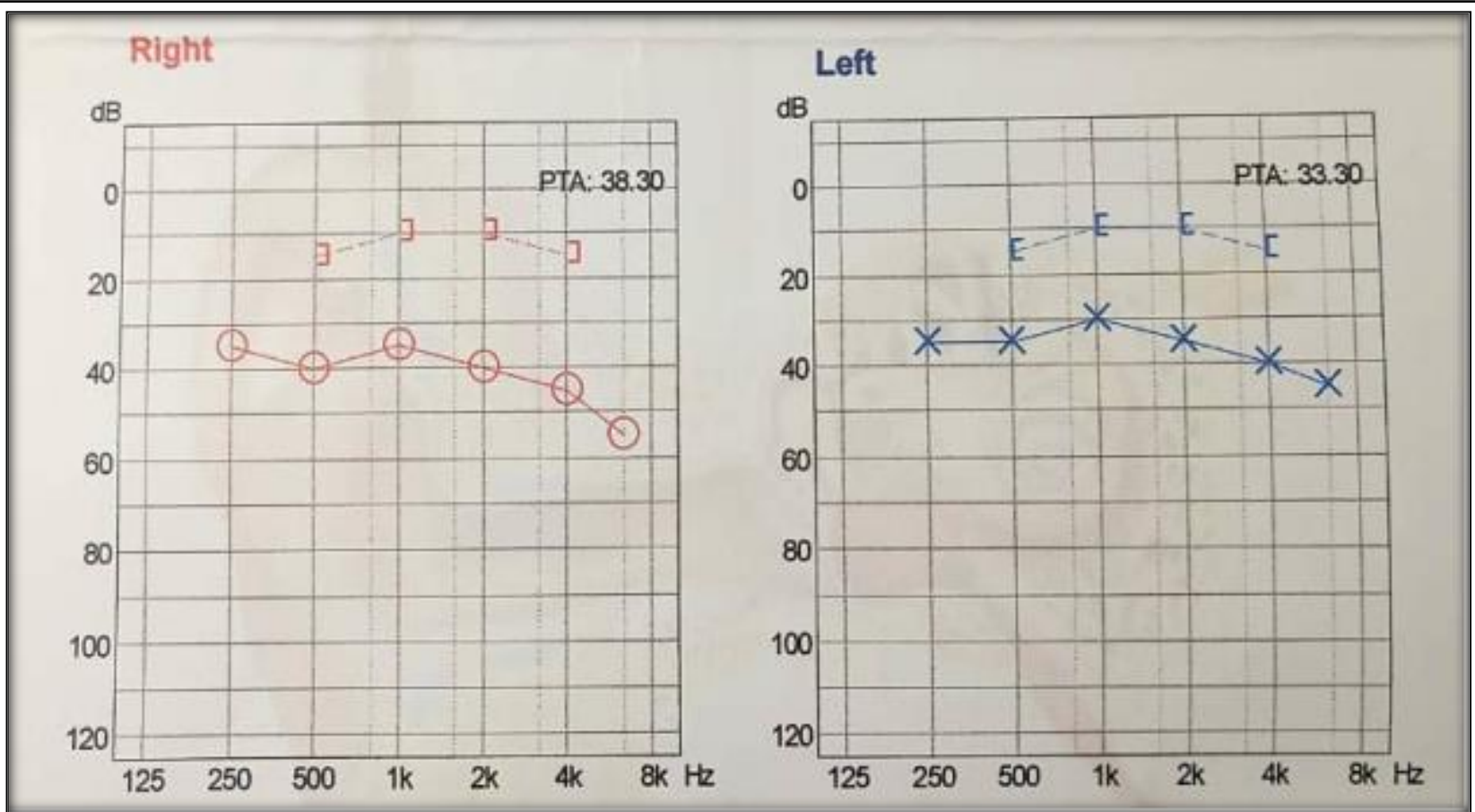

Figure 2: Pre-operative tympanogram of a patient showing type B curve.

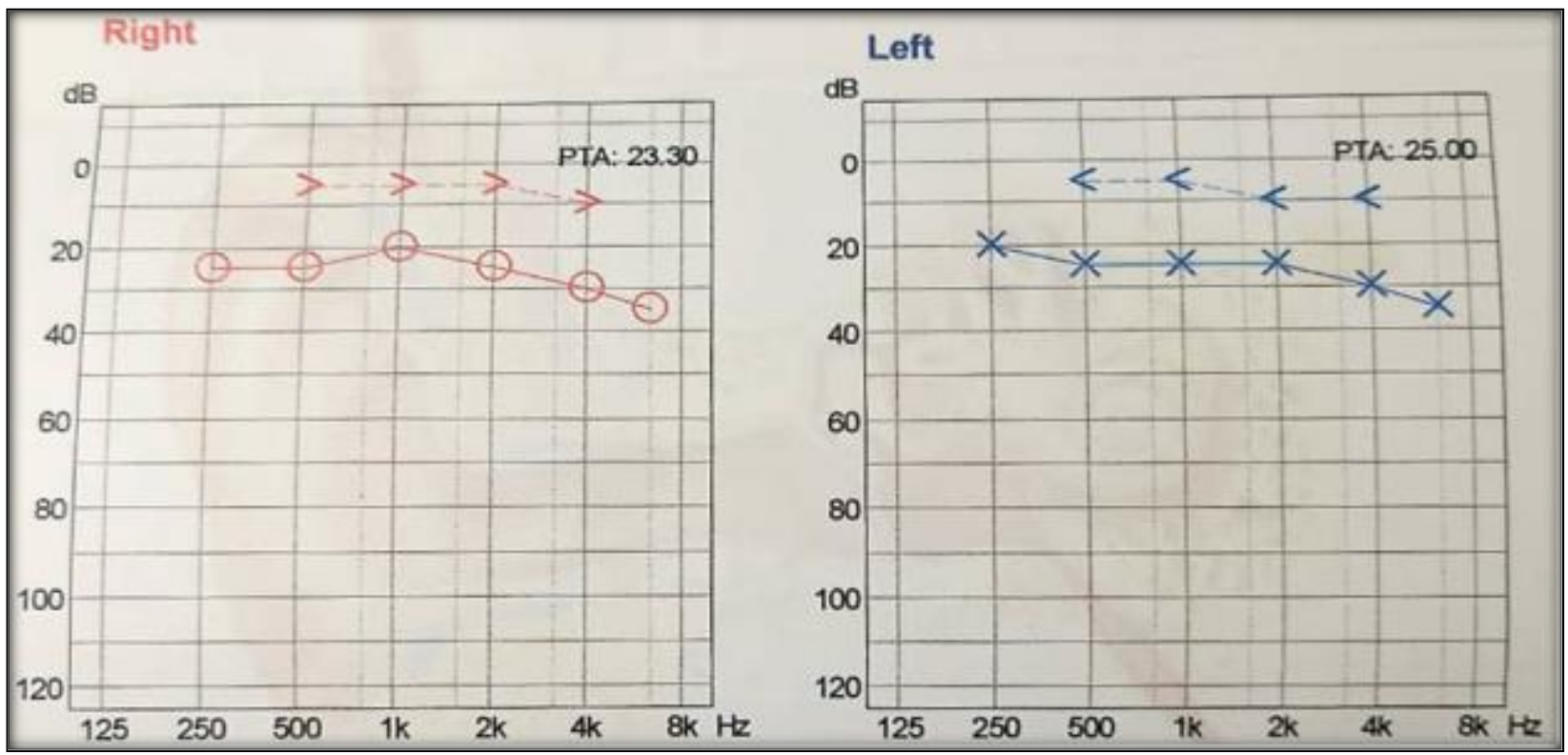

Figure 3: Post-operative impedance with improvement of OME.

\section{DISCUSSION}

The removal of the adenoids is presumed to eliminate the mechanical obstructive effect and or the source of nasopharyngeal infection. The failure of medical treatment to remedy chronic OME can probably be attributed to the 
Annals of International Medical and Dental Research E-ISSN: 2395-2822 | P-ISSN: 2395-2814

Vol-8, Issue-2 | March-April 2022

DOI: 10.53339/aimdr.2022.8.2.23

Page no- 174-179 | Section- Research Article (Otolaryngology)

mechanical effect that the adenoids have on the Eustachian tube opening. [14,15] The simultaneous removal of the tonsils is considered to be a viable option when a patient with OME has concomitant recurrent tonsillitis. Our findings demonstrated that adenotonsillectomy is a useful surgical procedure for treating persistent otitis media with effusion. Our results are in accordance with those of other studies. $16,17,18]$ For example, Maw studied 103 children, aged 2 to 12 years who still had persistent bilateral OME after undergoing a 12-week course of antihistamine treatment. These children were randomly assigned to one of three groups: an adenoidectomy group, an adenotonsillectomy group, and a nonsurgical control group. During surgery, one ear was intubated while the other served as a further intrapatient control ear to guess the degree of clearance and thus to help determine surgical success or failure. At 12 months of follow up, the combined success rate for the adenoidectomy and adenotonsillectomy groups was $71 \%$ compared with only $20 \%$ for the control group which had a highly significant difference. There was no statistically significant difference

\section{REFERENCES}

1. Maw AR, Bawden R. Factors affecting resolution of otitis media with effusion in children. Clin Otolaryngol Allied Sci. 1994;19(2):125-30. doi: 10.1111/j.1365-2273.1994.tb01195.x.

2. De Melker RA. Treating persistent glue ear in children. BMJ. 1993;306(6869):5-6. doi:10.1136/bmj.306.6869.5

3. Casselbrant ML, Brostoff LM, Cantekin EI, Flaherty MR, Doyle WJ, Bluestone CD, Fria TJ. Otitis media with effusion in preschool children. Laryngoscope. in success rates between the two surgical groups.

Another study of 48 children aged revealed that 2 to 14 years, who had persistent bilateral otitis media with effusion, enlarged adenoids and bilateral conductive hearing loss. [11] Half of these patients underwent adenoidectomy and the other half adenotonsillectomy. At six months post operatively, the overall success rate in terms of the resolution of middle ear effusion was $85 \%$, in which $82.6 \%$ are in the adenoidectomy group and $87.5 \%$ are in the adenotonsillectomy group; the difference was not statistically significant. [19]

Our findings concluded that adenotonsillectomy operations are effective for the treatment of persistent otitis media with effusion in children with recurrent tonsillitis and enlarged adenoid.

\section{CONCLUSIONS}

Our findings demonstrated that adenotonsillectomy operation is effective for the treatment of persistent otitis media with effusion due to chronic tonsillitis with enlarged adenoid.

1985;95(4):428-36. doi: 10.1288/00005537-19850400000011.

4. Katz S, Schmelzer B, Van Rompaey D. Surgical management of chronic otitis media with effusion. Acta Otorhinolaryngol Belg. 1995;49(1):69-73.

5. Bonding $\mathrm{P}$, Tos M. Grommets versus paracentesis in secretory otitis media. A prospective, controlled study. Am J Otol. 1985;6(6):455-60.

6. Roberts JE, Sanyal MA, Burchinal MR, Collier AM, Ramey CT, Henderson FW. Otitis media in early childhood and its relationship to later verbal and academic performance. Pediatrics. 1986;78(3):423-30. 
Annals of International Medical and Dental Research

E-ISSN: 2395-2822 | P-ISSN: 2395-2814

Vol-8, Issue-2 | March-April 2022

DOI: 10.53339/aimdr.2022.8.2.23

Page no- 174-179 | Section- Research Article (Otolaryngology)

7. Maw AR, Parker A. Surgery of the tonsils and adenoids in relation to secretory otitis media in children. Acta Otolaryngol Suppl. 1988;454:202-7. doi: 10.3109/00016488809125027.

8. Leiberman A, Bartal N. Untreated persistent middle ear effusion. J Laryngol Otol. 1986;100(8):875-8. doi: 10.1017/s0022215100100258.

9. Paradise JL. Does early life otitis media result in lasting developmental impairment? Why the question persists, and a proposed plan for addressing it. Adv perdiatr 1992; 39: 157-65.

10. Black NA, Sanderson CF, Freeland AP, Vessey MP. A randomised controlled trial of surgery for glue ear. BMJ. 1990;300(6739):1551-1556. doi:10.1136/bmj.300.6739.1551

11. Berman S, Roark R, Luckey D. Theoretical cost effectiveness of management options for children with persisting middle ear effusions. Pediatrics 1994; 93: 353- 63.

12. Rach GH, Zielhuis GA, van den Broek P. The influence of chronic persistent otitis media with effusion on language development of 2- to 4-yearolds. Int J Pediatr Otorhinolaryngol. 1988;15(3):25361. doi: 10.1016/0165-5876(88)90080-8.

13. Zielhuis GA, Rach GH, van den Broek P. Screening for otitis media with effusion in preschool children. Lancet. 1989;1(8633):311-4. doi: 10.1016/s01406736(89)91317-2.

14. Couriel JM. Glue ear: prescribe, operate, or wait? Lancet. 1995;345:3-4
15. Maw R, Bawden R. Spontaneous resolution of severe chronic glue ear in children and the effect of adenoidectomy, tonsillectomy, and insertion of ventilation tubes (grommets). BMJ. 1993;306(6880):756-60. 10.1136/bmj.306.6880.756.

16. Paradise JL, Bluestone CD, Rogers KD, Taylor FH, Colborn DK, Bachman RZ, et al. Efficacy of adenoidectomy for recurrent otitis media in children previously treated with tympanostomy-tube placement. Results of parallel randomized and nonrandomized trials. JAMA. 1990;263(15):2066-73.

17. Maw AR. Chronic otitis media with effusion (glue ear) and adenotonsillectomy: prospective randomised controlled study. Br Med J (Clin Res Ed). 1983;287(6405):1586-8. doi: 10.1136/bmj.287.6405.1586.

18. Austin DF. Adenotonsillectomy in the treatment of secretory otitis media. Ear Nose Throat J. 1994;73(6):367-9, 373-4.

19. Gates GA, Avery CA, Prihoda TJ, Cooper JC Jr. Effectiveness of adenoidectomy and tympanostomy tubes in the treatment of chronic otitis media with effusion. N Engl J Med. 1987;317(23):1444-51. doi: 10.1056/NEJM198712033172305.

Source of Support: Nil, Conflict of Interest: None declared 